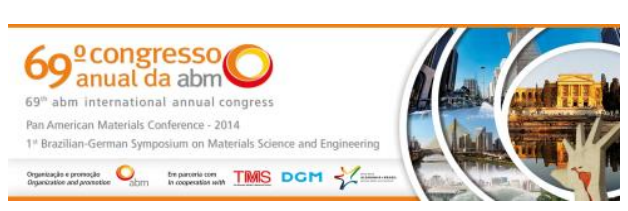

Tema: Gestão de Meio Ambiente e recuperação e tratamento de rejeitos

\title{
OTIMIZAÇÃO DA COLETA DE PÓ DA SINTERIZAÇÃO 2*
}

João Antonio Tavares Gouveia da Silva' Eiquiberto das Chagas Bustamante ${ }^{2}$ Claudinei Nogueira Soares ${ }^{3}$ Marcio Luiz da Costa

\section{Resumo}

Em outubro de 2012 a Gerencia de Sinterizações - GSR, da Companhia Siderúrgica Nacional - CSN, identificou a presença de material com granulometria maior que cinco $\mathrm{mm}$ na rota da coleta de pó da Máquina de Sinterização 2 (MS\#2), rota essa que direcionada diretamente para o silo de retorno quente. Essa representava uma oportunidade de melhoria, visto que apenas o material menor que $5 \mathrm{~mm}$ deveria retornar para o silo. Após amostragens de material foi possível identificar que, em média, $55 \%$ do material coletado poderia ser classificado como sinter produto ao invés de retorno quente, o que aumentaria o rendimento e produtividade da MS\#2. Utilizando a metodologia DMAIC e visando aperfeiçoar o processo a equipe da GSR avaliou todas as possíveis causas da geração do material grosseiro na coleta de pó. Em seguida projetou uma nova correia transportadora que desviasse o material da coleta de pó para o resfriador de sinter, ao invés de seguir para o silo de retorno quente, modificação essa que permitiu a classificação correta do material. Como resultado, a modificação feita pela equipe da GSR propiciou a redução da geração de retorno quente e, consequentemente, o consumo do mesmo. Desde o final de setembro de 2013 a máquina de sinterização número 2 consome em média $2 \%$ a menos de retorno quente, o que contribuiu para o aumento do rendimento do sínter e produção.

Palavras-chave: Sinterização; Retorno quente; Produtividade.

\section{Abstract}

\section{OPTIMIZATION OF COLLECTING DUST SINTERING 2}

In October 2012 the Sintering Management - GSR at Companhia Siderúrgica Nacional (CSN) - identified material with larger particle size than $5 \mathrm{~mm}$ on the route of the dust collection of sintering 2 . This route was directly head to hot scrap bin and represented an opportunity for improvement, once just materials with particle size under $5 \mathrm{~mm}$ should return to bin. After some samplings it became possible to identify that on average $55 \%$ of the collected material could be classified as sinter instead of hot scrap and this would increase the yield and productivity of machine number 2. Making use of DMAIC methodology and aiming at perfecting the process, the GSR team evaluated all the likely causes of the generation of this gross material on the dust collection and projected a new conveyor belt which departs the material from the dust collection to the sinter cooler instead of coursing to the hot scrap bin. This modification turned possible the accurate classification of the material. As a result, the team reduced the generation of hot return and consequently the consumption of it. Since the end of September 2013 the sinter machine number 2 takes on average 2\% less hot scrap contributing to the increase of yield and production.

Keywords: Sintering; Hot scrap; Productivity.

1 Engenheiro Mecânico, engenheiro de manutenção, GGRE, GSR, CSN, Volta Redonda, RJ, Brasil.

2 Técnico Mecânico, inspetor mecânico, GGRE, GSR, CSN, Volta Redonda, RJ, Brasil.

3 Técnico eletricista, inspetor eletricista, GGRE, GSR, CSN, Volta Redonda, RJ, Brasil.

4 Técnico em informática, supervisor de sinterização, GGRE, GSR, CSN, Volta Redonda, RJ, Brasil.

\footnotetext{
* Contribuição técnica ao $69^{\circ}$ Congresso Anual da ABM - Internacional e ao 14ํㅡㄹ ENEMET - Encontro Nacional de Estudantes de Engenharia Metalúrgica, de Materiais e de Minas, 21 a 25 de julho de 2014, São Paulo, SP, Brasil.
} 


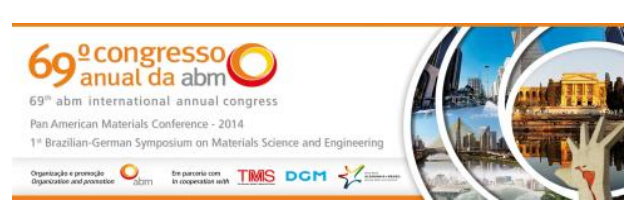

\section{INTRODUÇÃO}

A sinterização, por definição, é a aglomeração de finos de minério de ferro, fundentes e aditivos, formando uma massa porosa, através da semi-fusão redutora causada pelo calor produzido pela queima de combustível.

Os finos de minérios chamados de "sínter-feed" são enviados pelo pátio de matériasprimas e chegam à sinterização através de correias transportadoras. Eles são armazenados em silos para serem dosados juntamente com outras matérias primas, dentre as quais podemos citar o calcário, dolomita, cal, moinha de coque (combustível do processo), finos de sínter (material que devido a sua granulometria não pode ser consumido pelo alto-forno) e outros aditivos.

Todos esses componentes são transportados até um grande tambor cilíndrico rotativo denominado misturador, onde é adicionada água e formada uma mistura homogênea sólida. Na saída desse equipamento a mistura está na forma de micropelotas pronta para poder ser utilizada na máquina de sínter, onde é feita a sinterização propriamente dita.

A máquina possui uma esteira deslizante, sobre a qual é jogada a mistura, formando uma camada do material sobre a esteira. Esta passa na sua parte inicial através de um forno de ignição que, através da queima de gases, aplica uma chama sobre a superfície da camada. A moinha presente entra em combustão e fornece o calor necessário ao processo. Abaixo da esteira da máquina, existem tubos de vento que fazem uma sucção de ar. Desse modo, o combustível queima gradualmente em um movimento descendente, analogamente ao processo de queima de um cigarro. No seio dessa combustão ocorre uma série de reações químicas e todo o material presente é aglomerado. No fim da máquina, encontra-se um grande bloco de uma massa porosa denominada sínter.

Esse bloco é fragmentado em um quebrador de sínter, presente na saída da máquina. Logo abaixo dele, esse material passa pela Peneira de sínter quente para a separação do sinter mais grosso do fino, que será reaproveitado no processo. Em seguida, a fração de material mais grossa é enviada ao resfriador, para poder ser transportada em correias de borracha. Nas etapas seguintes, o sínter frio é separado de acordo com o tamanho dos grãos pelas Peneira Scalper e Peneira Frio. Desse modo, o sínter produto, no fim do seu beneficiamento, possui um tamanho adequado para ser consumido pelo alto-forno (figura 1).



Figura 1 - Fluxograma do Processo mostrando os principais equipamentos da Máquina de Sinterização.

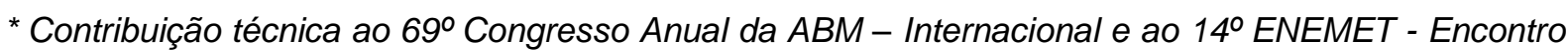
Nacional de Estudantes de Engenharia Metalúrgica, de Materiais e de Minas, 21 a 25 de julho de 2014, São Paulo, SP, Brasil. 


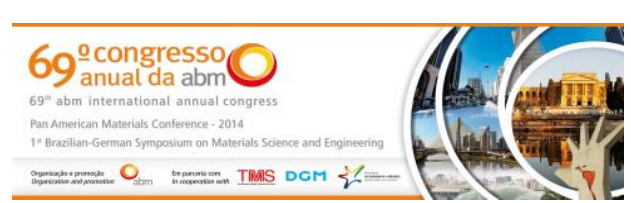

Atualmente a Usina Presidente Vargas da CSN (UPV) opera com três máquinas de sinterização podendo atingir a produção diária de 20.000 t/h. O projeto de otimização da coleta de pó foi realizado na Máquina de Sinterização 2 (MS\#2) concentrando-se na rota da coleta de pó que tem a função de direcionar os finos succionados pelo sistema de exaustão, decantados em silos e transportados via correias transportadoras para o silo de retorno quente (figura 2).

A equipe da GSR constatou a presença de material grosseiro, maior que $5 \mathrm{~mm}$ nesta rota, essa situação era indesejável para o processo visto que $100 \%$ do fluxo de material era direcionado para o silo de retorno quente, causando a classificação errada de sínter produto como retorno quente.

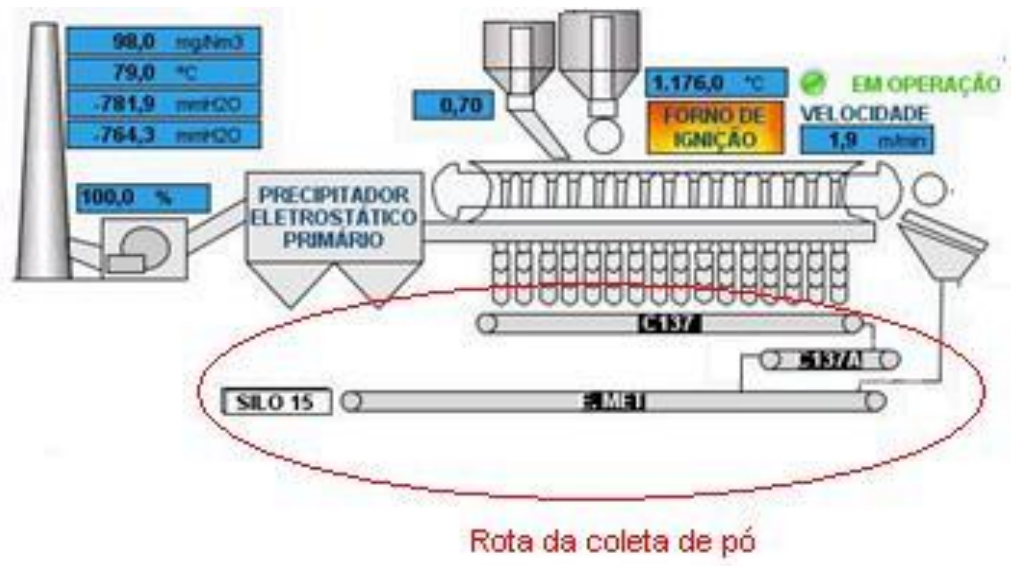

Figura 2 - Fluxograma da máquina de sinter e rota da coleta de pó

O objetivo desse trabalho foi identificar as possíveis causas do problema e definir a melhor solução para o mesmo. Para isso foi utilizada a metodologia DMAIC, visando atingir os seguintes resultados:

1) Classificar corretamente o sinter produto;

2) Reduzir a geração de retorno quente e consequentemente seu consumo;

3) Aumentar o rendimento da Máquina de sinterização e consequente a produtividade; e

4) Aumentar a disponibilidade de sínter para o processo seguinte (Altos Fornos).

\section{MATERIAIS E MÉTODOS}

\subsection{Objetivos}

O objetivo desse projeto é reduzir em $100 \%$ a presença de material > $5 \mathrm{~mm}$ no retorno quente proveniente da coleta de pó, visando à correta classificação do sinter produto e consequentemente o aumento da disponibilidade de sinter para os clientes da GSR.

\subsection{Metodologia}

A metodologia aplicada foi o DMAIC, pois a mesma visa o aperfeiçoamento do processo através da seleção correta dos processos que possam ser melhorados e das pessoas a serem treinadas, relacionando as técnicas estatísticas com as ferramentas da qualidade.

\footnotetext{
* Contribuição técnica ao 69ำ Congresso Anual da ABM - Internacional e ao 14ํㅡㄹ ENEMET - Encontro Nacional de Estudantes de Engenharia Metalúrgica, de Materiais e de Minas, 21 a 25 de julho de 2014, São Paulo, SP, Brasil.
} 


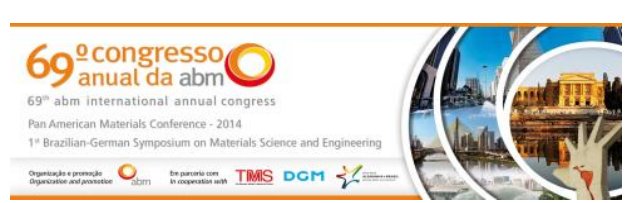

\subsubsection{Etapas do DMAIC}

- Definição: são escolhidos processos chaves que afetam as expectativas do consumidor e cujos desempenhos podem comprometer o alcance das metas estratégicas. São identificadas etapas desse processo, qual é o produto desse processo, quem é o cliente e quais suas expectativas.

- Medição: execução do mapa de processo, elaboração da matriz de causa e efeito. São escolhidos os processos a serem melhorados, avalia-se a habilidade dos processos atuais de fornecer os produtos de acordo com as exigências. Ao final desta fase, tem-se uma etapa crítica do processo e uma seleção de variáveis do processo a serem mais bem analisadas.

- Análise: os dados atuais do processo são analisados para se determinar o desempenho e a capacidade do mesmo. São identificados as causas raízes de defeitos e seus impactos.

- Melhoria: são desenvolvidas soluções para intervir no processo para reduzir significativamente os níveis de defeitos.

- Controle: controle estatístico do processo através de medições e monitoramento para manter as melhorias no desempenho.

A metodologia DMAIC não prevê retroalimentação, ou seja, um projeto bem aplicado não deve em nenhum momento retornar às fases anteriores. Se o resultado financeiro do projeto não for o esperado ou se o número de defeitos voltarem a subir, é porque não houve uma correta priorização das variáveis de entrada. A melhoria contínua não é feita revisando projetos já concluídos, mas aplicando a metodologia DMAIC para outros projetos ligados ao mesmo processo.

\subsubsection{Definição}

Por meio da metodologia, a equipe observou que a presença de material grosseiro na rota da coleta de pó na sinterização 2 , vide figura 3, comprometia o desempenho do processo, pois o sínter que deveria ser classificado como produto retornava para a máquina de sínter como resíduo.



Figura 3 - Material maior que cinco $\mathrm{mm}$ na correia $\mathrm{C}-137 \mathrm{~A}$

Para conhecer a real magnitude do problema a equipe coletou treze amostras de material da correia C-137A e enviou para o laboratório da GGPS afim classificar granulometricamente o material, analisando o gráfico 1 é possível comprovar a presença de aproximadamente $55 \%$ de sinter produto na rota da coleta de pó, essa amostragem serviu de comprovação para existência do problema e nos incentivou as buscar as causas do problema visando reverter às perdas do processo.

\footnotetext{
* Contribuição técnica ao $69^{\circ}$ Congresso Anual da ABM - Internacional e ao 14ํㅡㄹ ENEMET - Encontro Nacional de Estudantes de Engenharia Metalúrgica, de Materiais e de Minas, 21 a 25 de julho de 2014, São Paulo, SP, Brasil.
} 



Gráfico 1 - Presença de material > $5 \mathrm{~mm}$ por amostra coletada

\subsubsection{Medição}

O passo seguinte foi estratificar os dados levantados (gráfico 2) e formar um grupo de trabalho para investigar as causas principais do problema, utilizamos o brainstorming para identificar as possíveis causas do problema. Com isso a equipe identificou que a máquina de sinter número 2 apresentava três características que possibilitam a presença de material $>5 \mathrm{~mm}$ na coleta de pó, sendo todas elas parte integrante do projeto da máquina, inviabilizando assim a ação individual nos pontos abaixo, ver figura 4.

1) Folga existente na curva da máquina

2) Desgaste na parte inferior das caixas

3) Material agregado nas barras grelhas
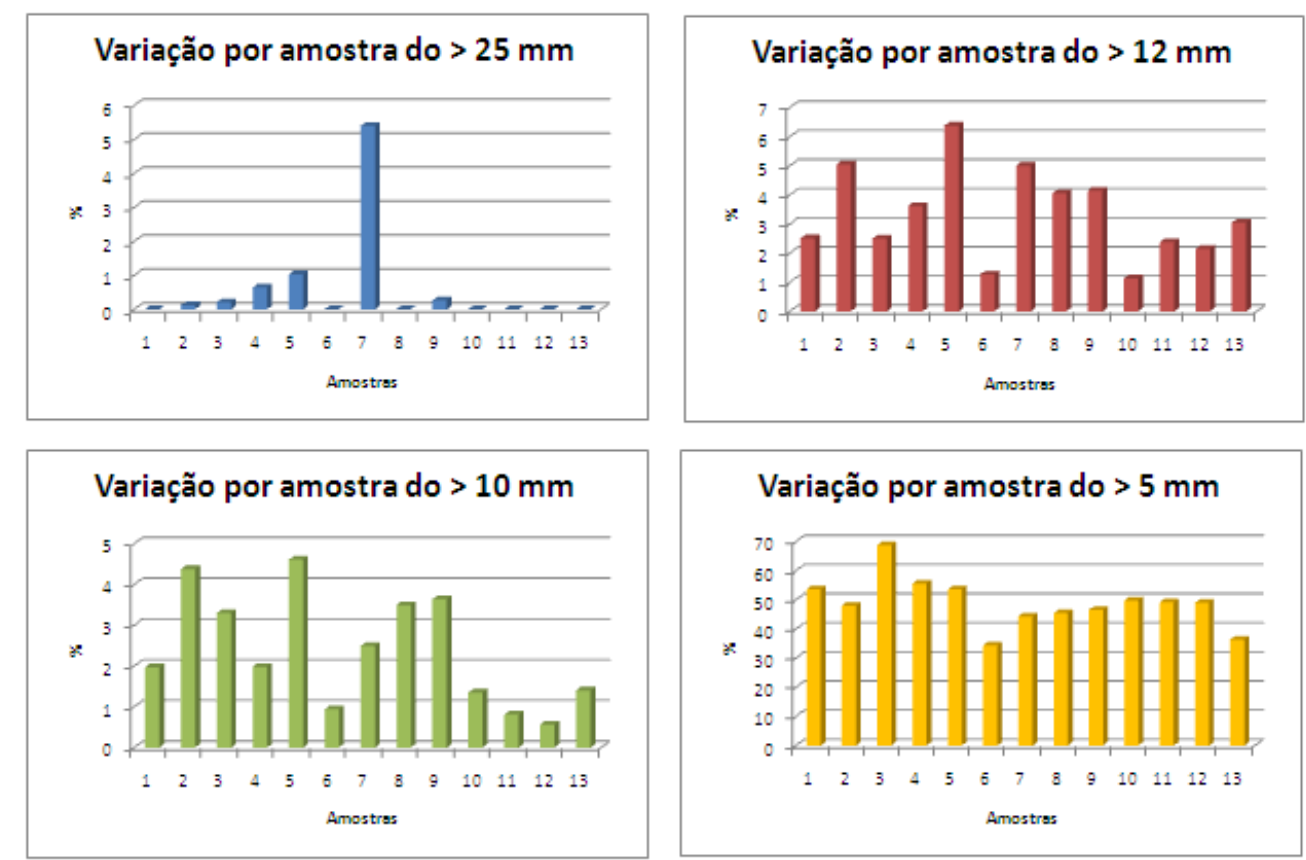

Gráfico 2 - Estratificação dos dados em quatro categorias

\footnotetext{
* Contribuição técnica ao $69^{\circ}$ Congresso Anual da ABM - Internacional e ao 14ํㅡㄹ ENEMET - Encontro Nacional de Estudantes de Engenharia Metalúrgica, de Materiais e de Minas, 21 a 25 de julho de 2014, São Paulo, SP, Brasil.
} 



Figura 4 - Causas identificadas para o problema de excesso de finos $>5 \mathrm{~mm}$

Nesse momento a equipe definiu que a meta a ser alcançada após implantação do projeto seria a eliminação do material maior que cinco $\mathrm{mm}$ proveniente da rota da coleta de pó, ou seja, reduzir em $100 \%$ a existência de material.

\subsubsection{Análise}

Nessa fase a equipe utilizou a matriz de priorização para definir quais causas seriam priorizadas (figura 5) para que a meta global fosse atingida e a ferramenta mostrou que as três causas apresentavam forte correlação com o problema identificado direcionando a equipe a desenvolver uma solução única para todas as causas.

A solução proposta foi a instalação de uma nova correia transportadora com a finalidade de redirecionar todo o fluxo de material para o resfriador de sinter, diferentemente do que acontecia no projeto original, onde $100 \%$ do material da coleta de pó seguia para o silo de retorno quente. A solução proposta possibilitou que o fluxo fosse classificado granulometricamente pelo peneirador existente (peneira fria). Tal modificação originou a necessidade de se revisar o mapa do processo conforme figura 6 .

\footnotetext{
* Contribuição técnica ao $69^{\circ}$ Congresso Anual da ABM - Internacional e ao 14ํㅡㄹ ENEMET - Encontro Nacional de Estudantes de Engenharia Metalúrgica, de Materiais e de Minas, 21 a 25 de julho de 2014, São Paulo, SP, Brasil.
} 


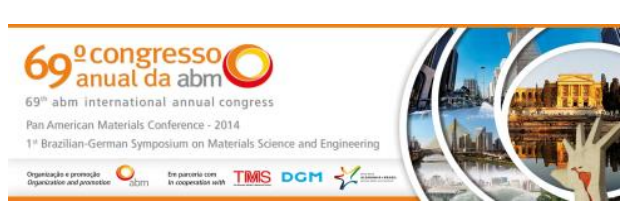

resultados. Para facilitar esse levantamento e acompanhamento das ações foi utilizada a ferramenta 5W2H (figura 7).

\begin{tabular}{|c|c|c|c|c|c|c|}
\hline $\begin{array}{c}\text { What } \\
\text { (Atividade) }\end{array}$ & Who & When & Why & Where & How & How Much \\
\hline Elaborar projeto básico & João Antonio & out/12 & $\begin{array}{l}\text { Para seguir } \\
\text { padrões }\end{array}$ & Sinterização $n^{\circ} 2$ & $\begin{array}{c}\text { Medindo, } \\
\text { desenhando e } \\
\text { calculando }\end{array}$ & RS 0,00 \\
\hline Especificar equipamentos e materiais & $\begin{array}{c}\text { João Antonio / } \\
\text { Eiquiberto/ } \\
\text { Claudinei }\end{array}$ & nov/12 & $\begin{array}{c}\begin{array}{c}\text { Para providenciar } \\
\text { recursos }\end{array} \\
\end{array}$ & Sinterização $n^{\circ} 2$ & $\begin{array}{l}\text { Calculando e } \\
\text { enquadrando } \\
\text { equipamentos }\end{array}$ & RS 0,00 \\
\hline Requisitar materiais & $\begin{array}{c}\text { Eiquiberto / } \\
\text { Claudinei }\end{array}$ & dez/12 & $\begin{array}{c}\text { Para dar inicio a } \\
\text { execucão }\end{array}$ & Sinterização $n^{\circ} 2$ & Utilizando o sigma & RS 876,31 \\
\hline $\begin{array}{c}\text { Abrir e programar requisição de } \\
\text { servico }\end{array}$ & $\begin{array}{l}\text { Eiquiveto / } \\
\text { Claudinei }\end{array}$ & $\mathrm{jan} / 13$ & $\begin{array}{l}\text { Para seguir } \\
\text { programacão }\end{array}$ & Sinterização $n^{\circ} 2$ & Utilizando o sigma & RS 0,00 \\
\hline Executar servico & Sankyu & $\operatorname{mar} / 13$ set $/ 13$ & Para implantar & Sinterização $n^{\circ} 2$ & Com uma equipe & R5 71.328,38 \\
\hline Atualizar Supervisório & Armando & ago/13 & \begin{tabular}{|c|} 
Para controlar \\
correia via painel \\
\end{tabular} & Sinterização $n^{\circ} 2$ & $\begin{array}{c}\text { Utilizando linguagem } \\
\text { apropriada }\end{array}$ & RS 0,00 \\
\hline $\begin{array}{l}\text { Atualizar desenho e lista de } \\
\text { equipamentos no sistema }\end{array}$ & João Antonio & out/13 & $\begin{array}{l}\text { Para registrar } \\
\text { modificação }\end{array}$ & Sinterização $n^{\circ} 2$ & Utilizando Cimage & RS 0,00 \\
\hline Acompanhar resultados & Equipe & out/13 & $\begin{array}{l}\text { Comprovar } \\
\text { ganhos }\end{array}$ & Sinterização $n^{\circ} 2$ & Estratificando dados & RS 0,00 \\
\hline
\end{tabular}

Figura 7 - Tabela 5W2H para construção da correia C-137B

$\mathrm{Na}$ fase de dimensionamento da correia utilizou-se uma ferramenta desenvolvida pela GSR que segue o manual da FAÇO, por meio de tabelas e fórmulas definimos as características básicas do transportador, como largura, inclinação, velocidade, potência do acionamento, entre outras. Em seguida desenvolvemos desenhos das estruturas, base de acionamento e calhas de transferência, todos os itens foram fabricados internamente com material disponível na área e mão de obra CSN. No mês de agosto/2013 aproveitamos um reparo geral programado para sinterização 2 , onde a produção de sinter ficou paralisada possibilitando as alterações necessárias. A figura 8 apresenta a correia C-137B pronta para operar com um investimento de $\mathrm{R} \$ 72.202,69$, Vale ressaltar que devido à alteração do fluxo do processo a equipe do projeto também atualizou o supervisório da máquina de sínter para que a operação pudesse ter total controle do processo, vide figura 9.

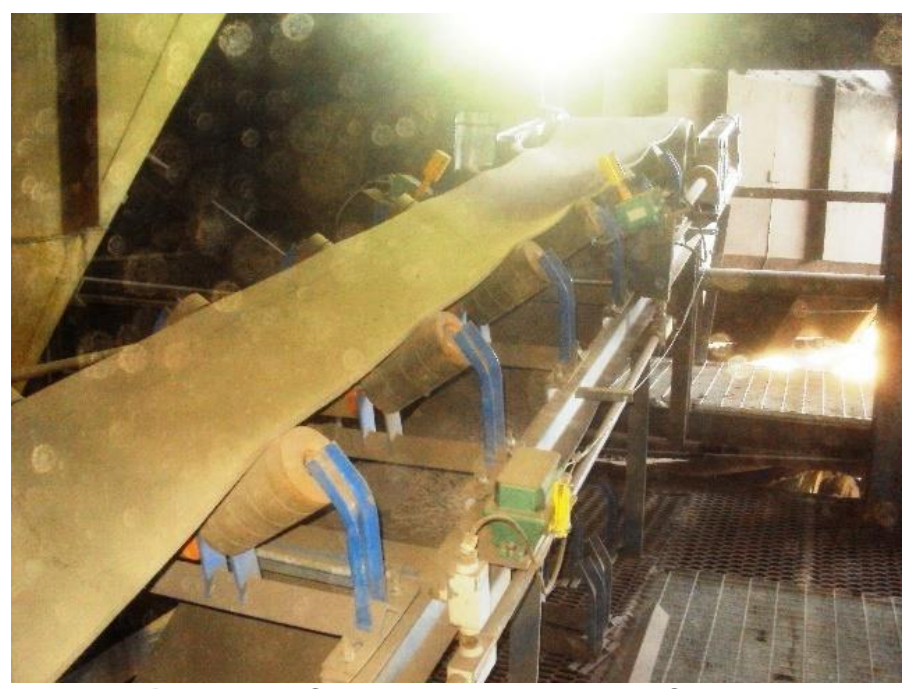

Figura 8 - Correia transportadora C-137B

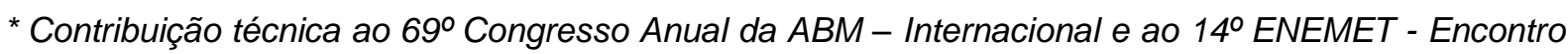
Nacional de Estudantes de Engenharia Metalúrgica, de Materiais e de Minas, 21 a 25 de julho de 2014, São Paulo, SP, Brasil.
} 

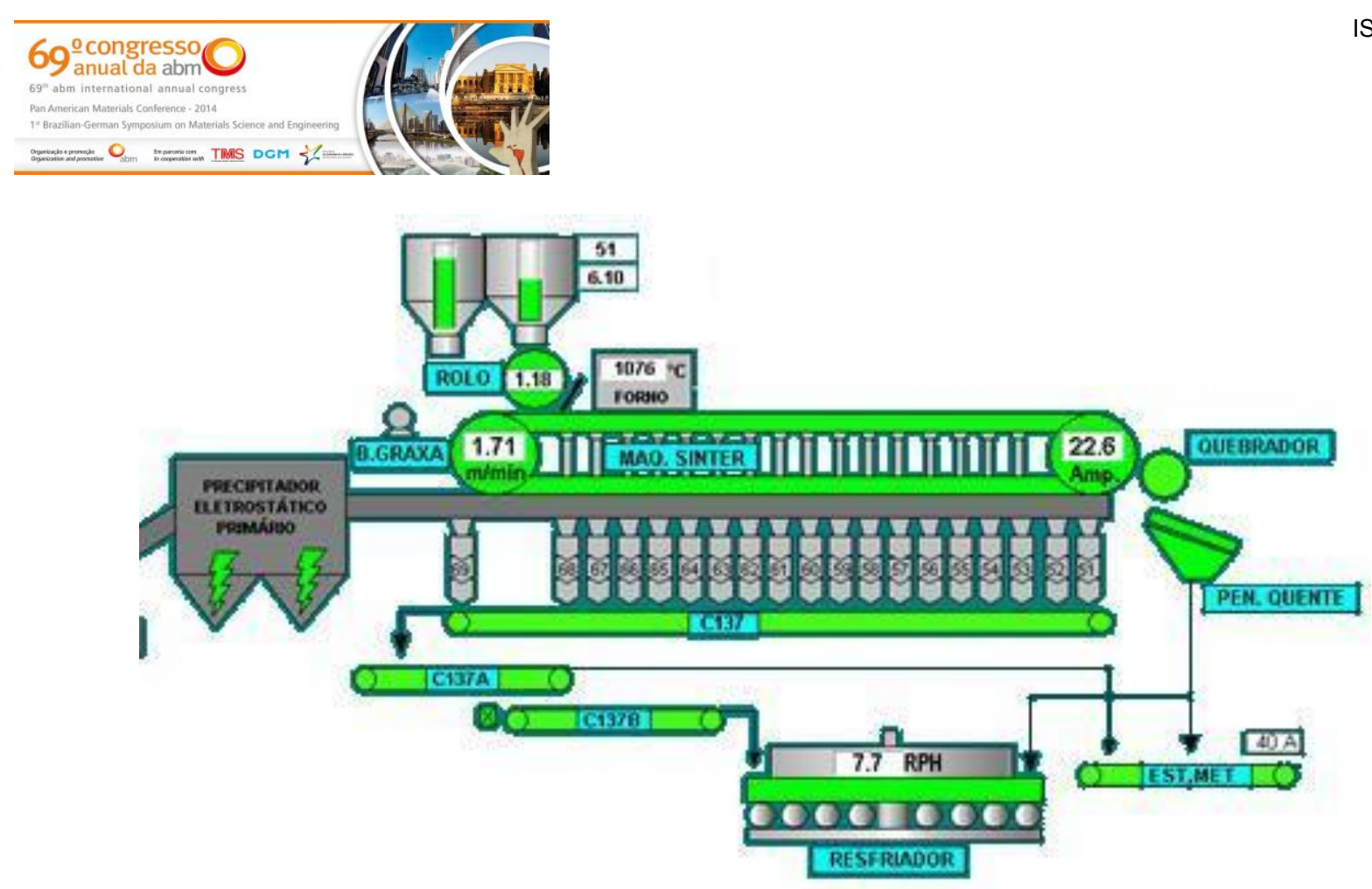

Figura 9 - Supervisório atualizado da Máquina de Sinterização 2

\section{RESULTADOS E DISCUSSÃO}

O projeto começou a operar no dia 25/09/2013, dois dias após a máquina número 2 retornar do reparo geral, a partir desse dia a equipe iniciou o processo de monitoramento do funcionamento da nova correia e as alterações na geração e consumo do retorno quente, esse monitoramento é realizado diariamente por meio de inspeção visual da granulometria do retorno proveniente da coleta de pó e também por meio da contabilização diária do consumo de retorno quente em t/h e \%. A partir dessas ações, a GSR garante a eficiência do projeto e também possibilitada à comparação dos dados atuais com os valores anteriores ao projeto para se contabilizar os ganhos atingidos.

O resultado alcançado pelo projeto ficou evidente desde o primeiro dia de operação da sinterização 2 pelo novo fluxo, foi possível eliminar a presença de material maior que $5 \mathrm{~mm}$ proveniente da coleta pó, vide gráfico 3, essa eliminação propiciou uma redução média de $2 \%$ do consumo de retorno quente junto às matérias primas (tabela 1), quando comparado aos valores médios de antes do projeto. (tabela 2), proporcionando o aumento do rendimento do sínter e ganho de produção diário.

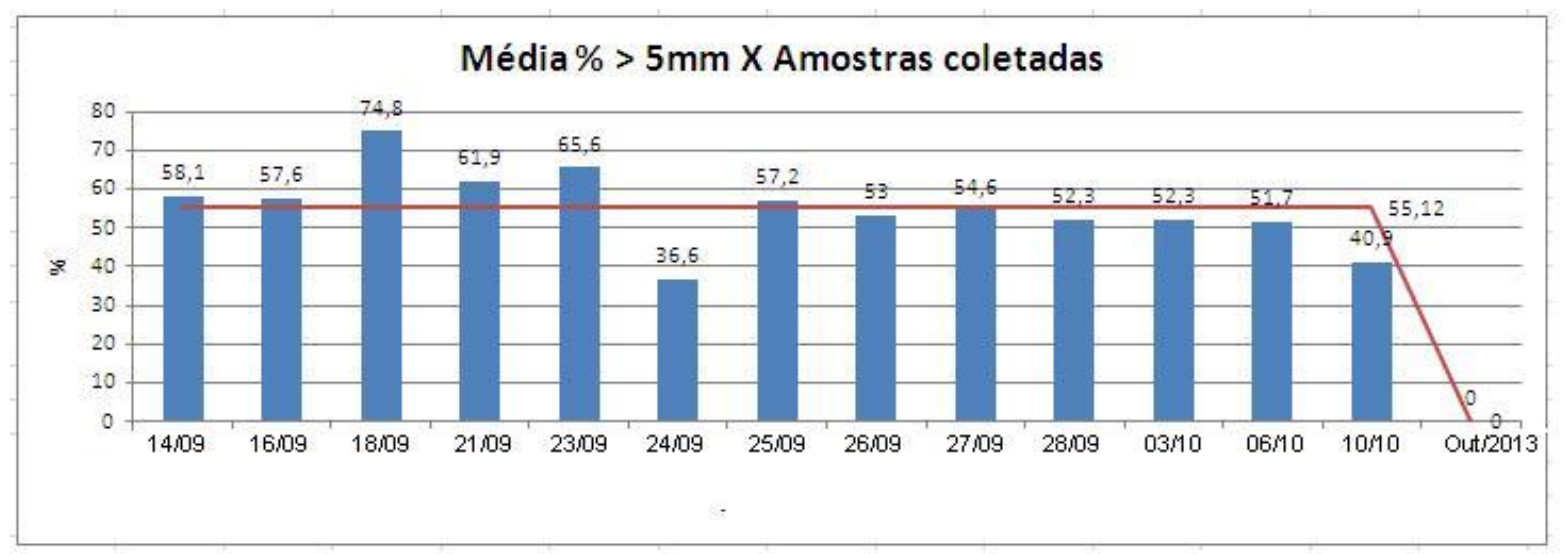

Gráfico 3 - Eliminação da presença de material > 5 mm na coleta de pó

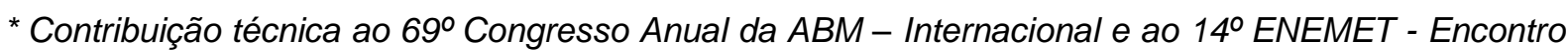
Nacional de Estudantes de Engenharia Metalúrgica, de Materiais e de Minas, 21 a 25 de julho de 2014, São Paulo, SP, Brasil.
} 


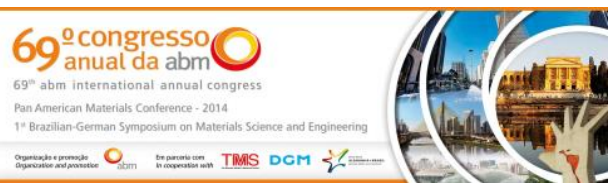

Tabela 1 - Demonstração da redução de consumo de retorno após implantação do projeto.

\begin{tabular}{|c|c|c|c|c|c|}
\hline Dia & $\begin{array}{c}\text { Taxa de } \\
\text { Alimentação }\end{array}$ & Consumo (\%) & Consumo $(\mathrm{t} / \mathrm{h})$ & Redução $(\mathrm{t} / \mathrm{h}$ ) & Redução (t/dia) \\
\hline quarta-feira, 25 de setembro de 2013 & $350 \mathrm{t} / \mathrm{h}$ & 10 & 32,88 & 2,97 & 71,28 \\
\hline quinta-feira, 26 de setembro de 2013 & $330 \mathrm{t} / \mathrm{h}$ & 10 & 29,75 & 2,24 & 53,86 \\
\hline sexta-feira, 27 de setembro de 2013 & $300 \mathrm{t} / \mathrm{h}$ & 8 & 22,47 & 4,64 & 111,41 \\
\hline sábado, 28 de setembro de 2013 & $280 \mathrm{t} / \mathrm{h}$ & 7,5 & 18,45 & 6,85 & 164,47 \\
\hline domingo, 29 de setembro de 2013 & $280 \mathrm{t} / \mathrm{h}$ & 7,5 & 19,78 & 6,12 & 146,92 \\
\hline segunda-feira, 30 de setembro de 2013 & $280 \mathrm{t} / \mathrm{h}$ & 7,5 & 17,87 & 7,17 & 172,13 \\
\hline terça-feira, 1 de outubro de 2013 & $350 \mathrm{t} / \mathrm{h}$ & 9 & 29,49 & 4,83 & 116,03 \\
\hline quinta-feira, 3 de outubro de 2013 & $350 \mathrm{t} / \mathrm{h}$ & 9 & 31,84 & 3,54 & 85,01 \\
\hline sexta-feira, 4 de outubro de 2013 & $350 \mathrm{t} / \mathrm{h}$ & 9 & 26,36 & 6,56 & 157,34 \\
\hline sábado, 5 de outubro de 2013 & $350 \mathrm{t} / \mathrm{h}$ & 9 & 30,04 & 4,53 & 108,77 \\
\hline segunda-feira, 7 de outubro de 2013 & $280 \mathrm{t} / \mathrm{h}$ & 9 & 26,67 & 2,33 & 55,97 \\
\hline
\end{tabular}

Tabela 2 - Consumo histórico de retorno quente para diferentes taxas de alimentação

\begin{tabular}{|c|r|r|}
\hline \multicolumn{3}{|c|}{ Antes do projeto (média de junho 2013 até agosto 2013) } \\
\hline Taxa de alimentação & Consumo RQ $(\%)$ & \multicolumn{1}{|c|}{$\mathrm{t} / \mathrm{h}$} \\
\hline $250 \mathrm{t} / \mathrm{h}$ & $13 \%$ & 30,94 \\
\hline 280 ate $319 \mathrm{t} / \mathrm{h}$ & $11,15 \%$ & 30,91 \\
\hline 320 até $340 \mathrm{t} / \mathrm{h}$ & $11,56 \%$ & 33,83 \\
\hline $350 \mathrm{t} / \mathrm{h}$ & $11,83 \%$ & 38,28 \\
\hline
\end{tabular}

Além dos ganhos operacionais, foi possível obteve-se o retorno financeiro, esses ganhos foram obtidos através da correta classificação do material que já era sínter produto e antes seguia como resíduo para ser misturado novamente com outras matérias primas, seguindo essa linha de raciocínio, utilizou-se os dados da tabela 1 para calcular o quanto de material maior que cinco $\mathrm{mm}$ passou a ser enviado para os Alto Fornos, outro fator a ser contabilizado como ganho financeiro é o aumento da disponibilidade de sínter e a possibilidade de substituição da Pelota pelo mesmo.

\section{CONCLUSÃO}

Com o projeto de otimização da coleta de pó desenvolvido e executado exclusivamente pelo corpo técnico da GSR (Gerência de Sinterizações), foi possível eliminar a presença de material maior que cinco $\mathrm{mm}$ da coleta de pó da sinterização número 2, reduzir o consumo de retorno quente, aumentar o rendimento de sinter e ganhar produtividade, alcançando assim, o maior aproveitamento dos recursos disponíveis. As alterações implementadas propiciaram ganhos operacionais não só para a GSR, mas também para os nossos principais clientes, os Altos Fornos.

\section{Agradecimentos}

A toda equipe da equipe da Gerência de Sinterizações - GSR pelo empenho demonstrado na implantação do projeto e a nossos familiares pelo constante apoio e incentivo.

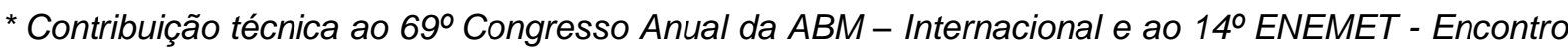
Nacional de Estudantes de Engenharia Metalúrgica, de Materiais e de Minas, 21 a 25 de julho de 2014, São Paulo, SP, Brasil.
} 


\section{BIBLIOGRAFIA}

1 Lima G. Dados técnicos das Sinterizações. Volta Redonda, RJ. Fundação General Edmundo de Macedo Soares e Silva - FUGEMSS. 1999.

2 Werkema C. Criando a cultura Seis Sigma. Nova Lima, MG: Werkema Ed. 2004.

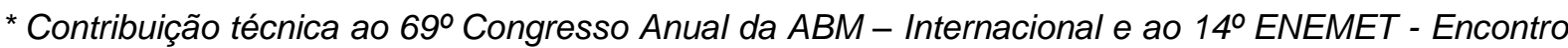
Nacional de Estudantes de Engenharia Metalúrgica, de Materiais e de Minas, 21 a 25 de julho de 2014, São Paulo, SP, Brasil. 